\title{
A study to design minimum data set of COVID-19 registry system
}

\author{
Javad Zarei ${ }^{1}$, Mohammad Badavi ${ }^{2}$, Majid Karandish³ ${ }^{3}$ Maryam Haddadzadeh Shoushtari ${ }^{4}$, \\ Maryam Dastoorpoor ${ }^{5}$, Farid Yousefi, ${ }^{6,7}$, Hanieh Raji ${ }^{4}$ and Maria Cheraghi ${ }^{8^{*}}$ (])
}

\begin{abstract}
Background: From the beginning of the COVID-19 pandemic, the development of infrastructures to record, collect and report COVID-19/data has become a fundamental necessity in the world. The disease registry system can help build an infrastructure to collect data systematically. The study aimed to design a minimum data set for the COVID-19 registry system.

Methods: A qualitative study to design an MDS for the COVID-19 registry system was performed in five phases at Ahvaz University of Medical Sciences in Khuzestan Province in southwestern Iran, 2020-2021. In the first phase, assessing the information requirements was performed for the COVID-19 registry system. Data elements were identified in the second phase. In the third phase, the MDS was selected, and in the four phases, the COVID-19 registry system was implemented as a pilot study to test the MDS. Finally, based on the experiences gained from the COVID-19 registry system implementation, the MDS were evaluated, and corrections were made.
\end{abstract}

Results: MDS of the COVID-19 registry system contains eight top groups including administrative (34 data elements), disease exposure (61 data elements), medical history and physical examination (138 data elements), findings of clinical diagnostic tests (101 data elements), disease progress and outcome of treatment (55 data elements), medical diagnosis and cause of death (12 data elements), follow-up (14 data elements), and COVID-19 vaccination (19 data elements) data, respectively.

Conclusion: Creating a standard and comprehensive MDS can help to design any national data dictionary for COVID-19 and improve the quality of COVID-19 data.

Keywords: Minimum data set, Registry system, COVID-19

\section{Background}

Although nearly 16 months have passed since the COVID-19 outbreak, and the vaccination is underway in most countries [1], there is still a long way to go to control the pandemic fully [2].

Inequality in vaccine access, insufficient access to vaccines in most poor countries [3-5], and COVID-19 virus

\footnotetext{
*Correspondence: mariacheraghi@gmail.com

${ }^{8}$ Social Determinant of Health Research Center, Department of Public Health, School of Health, Ahvaz Jundishapur University of Medical Sciences, Ahvaz, Iran

Full list of author information is available at the end of the article
}

mutations are some of the biggest challenges to control the COVID-19 pandemic, especially in developing countries [6]. Besides, there are still many questions about the long-term side effects of recovered patients and the impact of immunity from vaccination [7].

From the beginning of the pandemic, the rapid and surprising outbreak of COVID-19, its complex and unknown nature, has created data collection infrastructures for it, has become a fundamental necessity worldwide [8]. The fundamental step in designing a system to record, collect and report data on a particular disease is determining the target data elements [9]. One of the most well-known tools 
to determine data elements for disease registration and reporting systems is the minimum data set (MDS) [10]. MDS is a standardized set of data elements defined in a health information system to index the minimum amount of essential data for different users in healthcare sectors [11]. By precisely defining data elements, MDS creates a common language among all those involved in recording, collecting, analyzing, reporting, and interpreting data and ensures the collection of essential data [12, 13]. Furthermore, MDS helps improve medical records documentation, data comparability, data dictionary design, electronic data exchange among different healthcare systems and ultimately improve data quality $[12,14]$.

This feature has made MDS determination in disease registry systems one of the main steps to implement the system. Based on nature and application, the MDS data elements of a disease can be divided into two general categories of administrative and clinical data. The administrative data usually include demographic, socio-economic, address, phone number, patient referral data, and the main characteristic of a healthcare provider or healthcare center [15-18].

The clinical data vary depending on the type of diseases but generally include diagnosis, past medical history, laboratory findings, medical imaging findings, health interventions, disease course and progress, and outcome [16, 19]. In the case of COVID-19, the data structure is almost the same. Most case report forms, datasets, information systems, and MDSs designed for COVID-19 include patient demographic data, patient's addresses, and telephone, Profile of healthcare center, how did infected with COVID-19, early signs and symptoms, previous health condition and underlying diseases, COVID-19 testing, CT scan findings, and disease outcome [13, 17, 20-22].

In Iran, at the beginning of the COVID-19 epidemic, the Ministry of Health, as the custodian of the health system, set up two information systems for reporting COVID-19 in healthcare centers. Although these two systems collect basic information about patients with COVID-19, there are problems with data quality and data adequacy to support COVID-19 research [2]. Perhaps this is why several universities of medical sciences in Iran have launched a COVID19 registry system [22-26].

According to the important role of MDS designing in the success of a disease registry system, this study was performed to design a minimum data set for the COVID-19 registry system in Khuzestan province, southwestern Iran.

\section{Methods}

A qualitative study to design MDS for the COVID-19 registry system was conducted five phases at Ahvaz University of Medical Sciences in Khuzestan Province in southwestern Iran from March 2020 to March 2021.

\section{Phase 1: Study design and information needs assessment}

The purpose of this phase was to answer the following critical questions:

- What is the information that users such as researchers and policymakers of the registry program need for the future?

- According to those requirements, what information of COVID-19 should be recorded?

- What details are available about specific information that is recorded?

- What resources can identify the information?

- What are the minimum data elements?

- Given the urgency of setting up the COVID-19 registry system, what methods can be used to determine MDS?

According to the above-mentioned, a project team was formed under the supervision of the Diseases and Health Outcomes Registry Systems Office in Deputy of Research and Technology of Ahvaz Jundishapur University of Medical Sciences (AJUMS).

The project team reviews the titles of the COVID19 research proposals submitted to AJUMS as well as interviews with some researchers and experts in the field of disease registry. Moreover, the project team interview with senior managers of Deputy of Research and Technology in AJUMS. In addition, a survey was done on the structure and contents of health information systems such as SIB (an abbreviation for the Persian equivalent of "Integrated Health System") and hospital information system (HIS), Medical Care Monitoring Center "system (a system for reporting COVID-19 cases in hospitals) and the Management of Communicative Disease Prevention and Control system (a system for reporting COVID-19 cases from health centers). Also, the protocol and MDS of previous programs of disease registry at the university were studied. Furthermore, a list of the required information of the COVID-19 registry system were prepared.

In total, the following seven general areas were identified as information needed for the COVID-19 registry system in Khuzestan province:

1. Epidemiological study of COVID-19 prevalence and incidence.

2. The pattern of COVID-19 outbreaks and the factors affecting it.

3. The role of lifestyle in COVID-19 risk.

4. Symptoms, signs, and abnormal medical imaging and laboratory findings of COVID-19.

5. The course of the disease, drug treatment, and the patient's response to care. 
6. Outcomes of COVID-19|and the effect of underlying health conditions on its outcomes.

7. Follow up of treated patients.

\section{Phase 2: Identification of data elements}

In the second phase, the goal was to identify the data elements for each of the information needs specified in the previous phase. To identify the data elements, the project team first compiled a list of resources that could contribute to this goal. The resources included articles related to COVID-19, COVID-19 data collection tools, health information systems in Iran, medical records of patients with COVID-19, and expert opinions (such as specialist physicians, health information management specialists, and ...). Table 1 describes the information resources used, the search strategy, and the data acquisition method.

The collections form was used as an instrument. The form contained five sections: the name of the data element, class, application, value, and additional descriptions. The form was designed based on a literature review on MDSs [15, 27-33].

After collecting data, a list of data elements was prepared using the content analysis method. Duplicate or overlap items were removed. After that, similar items were categorized into the main class, subclass, data element, and values. In general, 475 data elements were identified in 18 subclasses and eight main classes.

\section{Phase 3: Select MDS}

At this phase, the purpose was to select MDS from the data elements identified in the previous phase. The expert panel method was used to select MDS. Firstly, a list of medical specialists who are members of the university hospitals of Ahvaz and involved in the care of patients with COVID-19 was prepared. Next, the project team was selected some specialists from the list based on indicators such as interest to join the registry and have a position in the relevant specialized department. The expert panels included medical specialists and some members of the project team. Table 2 shows the

Table 1 The information sources used for data gathering

\begin{tabular}{|c|c|c|}
\hline Information resources & Data collection methods & Details \\
\hline Articles & Literature review & $\begin{array}{l}\text { In PubMed database and Google search engine the terms "COVID- } \\
19 \text { " and "SARS-CoV-2" were searched to retrieve related articles } \\
\text { The inclusion criteria to select articles were English language, arti- } \\
\text { cle's relevance to the objectives, and the possibility of accessing } \\
\text { the full text } \\
\text { After searching and downloading the article, at the first the title and } \\
\text { the abstract were reviewed to choose the relevant articles. At the } \\
\text { second stage the full text of selected articles were considered }\end{array}$ \\
\hline \multirow[t]{2}{*}{ Data collection tools (forms, data sets, ...) } & Internet searching & $\begin{array}{l}\text { The COVID-19 questioners and reporting forms were googled } \\
\text { through the "COVID-19","SARS-COV-2","Coronavirus disease" } \\
\text { terms and in combination with the "Data collection form", 'Data } \\
\text { gathering form","'Minimum data set"," Data set", "Data dictionary", } \\
\text { "Questionnaire", "Form" terms in Persian and English languages } \\
\text { The search period was until April 15, } 2020\end{array}$ \\
\hline & Request information from experts & $\begin{array}{l}\text { A preliminary study showed that some Iranian universities of medi- } \\
\text { cal sciences were using a specific paper-based form to register } \\
\text { COVID-19 information. Most of the forms were used locally and } \\
\text { not available through the internet. However, since the most of } \\
\text { Iranian health information management experts who were using } \\
\text { the forms are member of social networks such as WhatsApp and } \\
\text { Telegram, the project team could access to the some of them }\end{array}$ \\
\hline National health information systems & On-site review of information systems & $\begin{array}{l}\text { The content and structure of the following Iranian health informa- } \\
\text { tion systems were reviewed } \\
\text { Management of Communicative Disease Prevention and Control } \\
\text { system, MCMC system, SIB, and HIS }\end{array}$ \\
\hline Patient medical record & Document review & $\begin{array}{l}\text { The structure of medical records in Iranian hospitals is hybrid. Part of } \\
\text { the patient's data is documented on paper, and the other part is } \\
\text { stored in information systems such as HIS electronically } \\
\text { We investigated the data elements of paper-based medical record } \\
\text { forms. Furthermore, the process of medical record documentation } \\
\text { was reviewed }\end{array}$ \\
\hline Experts (medical specialists) & Interview & $\begin{array}{l}\text { The attitudes of some medical specialists (pulmonologist, infectious } \\
\text { disease, radiologist, and internal medicine) on the minimum data } \\
\text { set of COVID-19 have been obtained using the interview }\end{array}$ \\
\hline
\end{tabular}


demographic characteristics of participants in the expert panels. In the panels, a list of data elements that scaled with the Likert score (1-5) was distributed among participants. During the meetings, data element and their values and feasibility for collection it such as accessibility, method, and time of gathering was discussed. Finally, the primary data elements for MDS were selected.

Furthermore, some new data elements suggested by experts were considered. All data elements with more than $50 \%$ of agreement among panelists were elected to apply in the primary MDS.

\section{Phase 4: Field-testing}

Based on primary MDS, we developed web-based COVID-19 registry software (available at http://covid. ajums.ac.ir) using the Rapid Application Development (RAD) technique. In addition to registry software, paperbased forms were designed to help collect data from the hospitals. In the paper forms and registry software, data elements were divided into six top groups: administrative, disease exposure, medical history and physical examination, clinical diagnostic test findings, disease progress and outcome of treatment, and follow-upi/data. A WhatsApp group that had the project team and experts members was created. The designed forms were shared in the group, and the members were asked to comment on them. After reviewing the members' comments, the approved comments were applied to the forms.

In the next step, to evaluate the following items, the registry program was tested as a pilot in Razi hospital in Ahvaz city (the capital of Khuzestan province). The

Table 2 Demographic characteristics of participants in the expert panel

\begin{tabular}{lll}
\hline Demographic characteristics & Frequency & Present (\%) \\
\hline Sex & 5 & 50 \\
Male & 5 & 50 \\
Female & & \\
Education & 3 & 30 \\
Ph.D. & 3 & 30 \\
Medical specialist & 4 & 40 \\
Fellowship & & \\
Specialty & 3 & 30 \\
Pulmonology & 1 & 10 \\
Infectious disease & 1 & 10 \\
Internal medicine & 1 & 10 \\
Cardiology & 1 & 10 \\
Health information management & 1 & 10 \\
Epidemiology & 1 & 10 \\
Laboratory science & 1 & 10 \\
Emergency medicine &
\end{tabular}

evaluated items included structure and content of the designed forms, data values, mandatory fields in the registry software, and identify new data needs. Razi is a 200bed university hospital considered the main hospital for admitting patients with COVID-19 since late February 2020, when the first positive COVID-19 case was diagnosed in Khuzestan province.

An official letter was sent to Razi Hospital and to make an announcement to invite those interested in participating in the COVID-19 registry program. The Eleven staff of the hospital were selected to participate in the registry system. After training the participants, the registry system was implemented as a pilot for 3 weeks. The participants joined a WhatsApp group to share their opinions and suggestions regarding the data elements, the data collection forms, and the registry software. In addition, two persons of participants were selected to be responsible for monitoring the data collection process and data quality control. They documented all weaknesses and problems related to the data collection process and submitted their recommendations daily. At the end of the pilot, the comments were summarized and submitted to the project manager. Based on the results of the pilot study, some changes were made to MDS, forms, and registry software. The changes included deleting and adding some data elements, renaming the subclass title or data element field name, and modifying their values.

\section{Phase 5: Evaluate and modify MDS}

At the end of May 2020, the COVID-19 registry program was implemented. Six months later, the MDS was evaluated based on the feedback obtained from the initial data analysis and the experiences gotten of the implementation process.

We modified the MDS, removed useless data elements, and added new data elements to the data collection forms and registry software. Finally, when the COVID-19 vaccination was launched in March 2021 in Ahvaz, a new top group was created for recording the vaccination data.

\section{Results}

In the second phase of the study, 375 data elements were categorized into 14 subclasses and eight main classes based on a review of information resources. Then, in the third phase, according to the output of Expert panels, 11 data elements were eliminated, and 25 new data elements were added to the MDS.

Also, according to expert comments, some changes were made in the subclasses, and the number of subclasses increased to 27. For example, the clinical laboratory tests class was divided into five subclasses: hematology test, biochemistry tests, arterial blood gas test, hemostasis test, and other diagnostic tests finding. 
After the pilot study, 12 data elements were deleted due to the impossibility of collecting in the routine process of patients with COVID-19 care. Also, 25 new data elements suggested by the participants and approved by the project team were added to the MDS. For example, the ICD10 code and the causes of death recorded in the death certificate were added.

Since to avoid users' misconceptions and to become data elements transparent, the titles of 13 data elements were renamed.

The values of 26 data elements were also modified in the software. For example, values related to education, job title, and discharge status were changed.

Also, pilot study results showed that the data collection process should be in accordance with the patient care process. Furthermore, to facilitate data collection, the structure of data collection forms and the registry software should be as similar as possible to the medical record forms and HIS.

In the fifth phase, the database was evaluated and modified again. The modifications covered adding a new top group, two main classes, 12 subclasses, and 59 new data elements, as well as removing five subclass and 26 useless data elements. For example, due to the COVID-19 outbreak in Khuzestan province, some data element such as "disease exposure data top group", and two subclass including "observance of safety measures" and "contact with health care facility" have lost their importance, and finally were removed.

The final MDS for the COVID-19 registry system was divided into eight top groups, 18 main classes, 70 subclasses, and 434 data elements (Table 3). The details of the final MDS are shown in Tables 4, 5, 6, 7, 8, 9, 10 and 11.

In general, the administrative data group includes two main classes, five subclasses, and 34 data elements (Table 4).

In general, the disease exposure data group includes two main classes, seven subclasses, and 61 data elements (Table 5).

In general, the medical history and physical examination data group embraces four main classes, 27 subclasses, and 138 data elements (Table 6).

Table 3 Overall view MDS for the COVID-19 registry system

\begin{tabular}{|c|c|c|c|c|}
\hline Rank & Top groups & $\begin{array}{l}\text { The number of main } \\
\text { classes }\end{array}$ & $\begin{array}{l}\text { The number of sub } \\
\text { class }\end{array}$ & $\begin{array}{l}\text { The number of } \\
\text { data element }\end{array}$ \\
\hline 1 & Administrative data & 2 & 5 & 34 \\
\hline 2 & Disease exposure data & 2 & 7 & 61 \\
\hline 3 & Medical history and physical examination data & 3 & 27 & 138 \\
\hline 4 & Clinical diagnostic test findings data & 3 & 12 & 101 \\
\hline 5 & Disease progress and outcome of treatment data & 3 & 7 & 55 \\
\hline 6 & Medical diagnosis and cause of death data & 3 & 6 & 12 \\
\hline 7 & Follow-upfidata & 1 & 4 & 14 \\
\hline 8 & COVID-19 vaccination data & 1 & 2 & 19 \\
\hline Total & & 18 & 70 & 434 \\
\hline
\end{tabular}

Table 4 Administrative data about a probable or confirmed cases of COVID-19

\begin{tabular}{|c|c|c|}
\hline Main class & Sub class & Data elements \\
\hline \multirow[t]{3}{*}{ Individual profile } & Demographic & $\begin{array}{l}\text { National identity number, Medical record number } \\
\text { Patient name, patient surname, father's name, sex } \\
\text { Date of birth, blood groups (types of blood) }\end{array}$ \\
\hline & Socio-economic & $\begin{array}{l}\text { Marital status, number of family members, Patient ethnicity, educational degree, } \\
\text { labor force status, job title, work address (country, province, city, town/village, } \\
\text {...) }\end{array}$ \\
\hline & Adders & $\begin{array}{l}\text { Living status, inhabitancy in residential institution (old people's home, prison, } \\
\text { military camp,...), type of residence (urban, suburban, rural), residential } \\
\text { address (country, province, city, town/village, region/neighborhood, ...), } \\
\text { temporary address (country, province, city, town/village, region/neighbor- } \\
\text { hood, ...), zip code, telephone number, mobile phone number, emergency } \\
\text { call number }\end{array}$ \\
\hline \multirow[t]{2}{*}{ Healthcare Provider Profile } & Healthcare facility profile & ID, Healthcare center name, Healthcare center type, Health care center affiliation \\
\hline & Registrar personnel profile & ID, name, surname, role, specialty \\
\hline
\end{tabular}


Table 5 Disease exposure data about a probable or confirmed case of COVID-19

\begin{tabular}{|c|c|c|}
\hline Main class & Sub class & Data element \\
\hline \multirow[t]{2}{*}{ Exposure data } & Direct contact with an infected person & $\begin{array}{l}\text { Has the person had contact with a probable or confirmed case in the } 14 \text { days before the } \\
\text { onset of symptoms? } \\
\text { If yes, The place of encounter: } \\
\text { Health care center, hypermarket/shop, gas station, bus/metro, airport/railway station, res- } \\
\text { taurant/coffee, public administrative area, bank, home, residential institution, weddings, } \\
\text { family parties, mourning ceremonies, workplace, other(s), please specify } \\
\text { If yes, and the patient knows the person (probable or confirmed case), please state the } \\
\text { person's details: } \\
\text { Name and surname, phone number, address }\end{array}$ \\
\hline & Travel & $\begin{array}{l}\text { Has the case travelled in the } 14 \text { days before the symptom onset? } \\
\text { If yes: Country, province/state, city, date of departure from the place, details (please } \\
\text { explain) }\end{array}$ \\
\hline \multirow[t]{5}{*}{ Case finding } & Case finding process & $\begin{array}{l}\text { Refer to a health care center with symptoms of COVID-19, random screening and identi- } \\
\text { fication of the patient, transfer from other health care centers, case finding by tracking } \\
\text { who had close contact with previously identified patients, other(s), please specify }\end{array}$ \\
\hline & First symptom of disease & $\begin{array}{l}\text { Fever, chills, dry cough, nasal congestion, runny nose, sore throat, mucus or phlegm, short- } \\
\text { ness of breath, constant pain or pressure in chest, tiredness, muscle aches, headache, } \\
\text { loss of smell or taste, fatigue, diarrhea, nausea or vomiting, loss of appetite, dry mouth, } \\
\text { other(s), please specify, date of first symptom }\end{array}$ \\
\hline & First visit to a healthcare center & Type of admission (ambulatory, impatient), date of admission, name of healthcare center \\
\hline & COVID-19 testing & $\begin{array}{l}\text { Type of tests (RT-PCR, antigen/rapid test), sampling method (nasopharyngeal swab, throat } \\
\text { swab), date of sampling } \\
\text { Test result (positive, negative), laboratory name, date of confirmed disease }\end{array}$ \\
\hline & Infection with mutated strains of COVID-19 & $\begin{array}{l}\text { Infection with mutated strains of COVID-19, type of variant (B.1.1.7, B.1.351, P.1, B.1.427, } \\
\text { B.1.429, B.1.617, ..) }\end{array}$ \\
\hline
\end{tabular}

In general, the clinical diagnostic test findings data group consists of three main classes, 12 subclasses, and 101 data elements (Table 7).

In general, the disease progress and outcome of treatment data group includes three main classes, 12 subclasses, and 55 data elements (Table 8).

In general, medical diagnosis and cause of death data group consists of three main classes, six subclasses, and 12 data elements (Table 9).

In general, follow-up ' idata group embraces one main class, three subclasses, and 14 data elements (Table 10).

In general, the COVID-19 vaccination" "data group includes one main class, two subclasses and, and 19 data elements (Table 11).

\section{Discussion}

A study on the coronavirus family showed that creating a data set can help disease control intervention [35]. The lack of MDS is one of the technical barriers to data sharing in public health [36]. Therefore, from the beginning of the COVID-19 outbreak, World Health Organization has recommended a "Revised case reporting form for 2019 Novel "Coronavirus of confirmed and probable cases" to report COVID-19 cases and has requested national authorities to design MDS for reporting COVID-19 based on the form [37]. However, that form may not be suitable for the COVID-19 registry system. Since the many aspects of COVID-19 were unknown at the beginning of the pandemic, there were a lot of questions about the disease in the minds of scientists and health policymakers. Therefore, the COVID-19 registry system should provide comprehensive information [2]. This study tried to fulfill that requirement. The approach used to design MDS included identifying the required data elements, the initial design of MDS, the pilot test, and modification of MDS based on the results obtained from the implementation. Stanfill et al., in the study entitled "Health information management best practices for quality health data during COVID-19 global pandemic", had the same approach as our study. They emphasized identifying the data elements, considered the expected results, and evaluated the output data to justify data elements [38].

In the MDS for the COVID-19 registry system, 396 data elements were identified in eight top groups, 17 main classes, and 67 subclasses. The first top group included administrative data that are commonly used to identify and register patients, identify a healthcare institution, reimburse the costs of healthcare services [39, 40], do medical research, and carry out a survey on the outcome and quality of healthcare $[21,41]$.

The second top group was disease exposure data. These data can help to determine the method of individual transmission of disease and identify early signs and symptoms. Therefore, in order to show how the patient 
Table 6 Medical history and physical examination data about a probable or confirmed case of COVID-19

\begin{tabular}{|c|c|c|}
\hline Main class & Sub class & Data element \\
\hline \multirow[t]{6}{*}{ Signs and symptoms at the time of admission } & General signs and symptoms & $\begin{array}{l}\text { Fever, chills, tiredness, muscle aches, headache, loss of } \\
\text { smell or taste, eye congestion, dry mouth, other(s), } \\
\text { please specify }\end{array}$ \\
\hline & Respiratory signs and symptoms & $\begin{array}{l}\text { Dry cough, sneezing, runny nose, dyspnea/tachypnea, } \\
\text { constant pain or pressure in chest, nasal congestion, } \\
\text { exudative pharyngitis, mucus or phlegm, hemoptysis, } \\
\text { other(s), please specify }\end{array}$ \\
\hline & Digestive signs and symptoms & $\begin{array}{l}\text { Diarrhea, nausea or vomiting, loss of appetite, abdominal } \\
\text { pain, constipation, other(s), please specify }\end{array}$ \\
\hline & Nervous signs and symptoms & $\begin{array}{l}\text { Fatigue, decreased consciousness, Glasgow coma scale/ } \\
\text { score (GCS), functional limb weakness, other(s), please } \\
\text { specify }\end{array}$ \\
\hline & Cardiovascular signs and symptoms & $\begin{array}{l}\text { Orthopnea, ischemia, anginå, arrhythmias, other(s), please } \\
\text { specify }\end{array}$ \\
\hline & Others signs and symptoms & $\begin{array}{l}\text { Rash on skin, discoloration of fingers or toes, other(s), } \\
\text { please specify }\end{array}$ \\
\hline \multirow[t]{6}{*}{ Review of systems at the time of admission } & Vital signs & $\begin{array}{l}\text { Pulse rate, respiratory rate, blood pressure, temperature, } \\
\text { level of consciousness }\end{array}$ \\
\hline & Thorax & $\begin{array}{l}\text { Heart murmurs, wheezing, stridor, pleural friction rub, } \\
\text { ventricular gallop, atrial gallop, other(s), please specify }\end{array}$ \\
\hline & Abdomen & Tenderness, organomegaly, other(s), please specify \\
\hline & Limbs & Edema, weak pulse, other(s), please specify \\
\hline & Height and weight & Height, weight, BMI > 30 \\
\hline & Other & $\begin{array}{l}\text { Others signs and symptoms, please specify, additional } \\
\text { comment }\end{array}$ \\
\hline \multirow[t]{15}{*}{ Underlying conditions and comorbidity } & Cardiovascular diseases & $\begin{array}{l}\text { Hypertension, heart failure, arrhythmia, ischemic heart } \\
\text { disease, other(s), please specify }\end{array}$ \\
\hline & Endocrine and metabolic diseases & $\begin{array}{l}\text { Type } 1 \text { diabetes mellitus, Type } 2 \text { diabetes mellitus, unspeci- } \\
\text { fied diabetes mellitus } \\
\text { If yes, Had the patient's diabetes be controlled? } \\
\text { Metabolic syndrome, other(s), please specify }\end{array}$ \\
\hline & Malignant neoplasms & $\begin{array}{l}\text { Morphology, primary site, secondary site } \\
\text { If yes, Does the patient receive chemotherapy? } \\
\text { If yes, Does the patient receive radiotherapy? } \\
\text { Additional comment }\end{array}$ \\
\hline & Respiratory diseases & $\begin{array}{l}\text { Chronic obstructive pulmonary disease (COPD), bronchi- } \\
\text { ectasis, interstitial lung disease (ILD), asthma, other(s), } \\
\text { please specify }\end{array}$ \\
\hline & Immunodeficiency & $\begin{array}{l}\text { HIV/AIDS, congenital immunodeficiency disorders, } \\
\text { other(s), please specify }\end{array}$ \\
\hline & & $\begin{array}{l}\text { The patient is being treated with corticosteroids or immu- } \\
\text { nosuppressant medications } \\
\text { If yes, Name of medications used, medications dosage }\end{array}$ \\
\hline & Chronic neurological or neuromuscular diseases & $\begin{array}{l}\text { Cerebral palsy, paraplegia, hemiplegia, multiple sclerosis } \\
\text { (MS), old cerebrovascular accident (CVA),other(s), please } \\
\text { specify }\end{array}$ \\
\hline & Renal diseases & $\begin{array}{l}\text { Chronic kidney disease, end stage renal disease (ESRD), } \\
\text { other(s), please specify }\end{array}$ \\
\hline & Liver diseases & $\begin{array}{l}\text { Liver failure, liver cirrhosis, hepatitis (A, B, C), other(s), } \\
\text { please specify }\end{array}$ \\
\hline & Other important underlying conditions and comorbidity, & $\begin{array}{l}\text { Prematurity (infant), mental retardation, other important } \\
\text { underlying conditions and comorbidity, please specify }\end{array}$ \\
\hline & Pregnancy, childbirth and the puerperium & Pregnancy, gestational age \\
\hline & & Childbirth in the last 6 weeks \\
\hline & Menopause & Menopause, menopause age \\
\hline & Smoking, drugs abuse and alcohol & $\begin{array}{l}\text { Cigarettes, hookahs, alcohol, drug's abuse, additional } \\
\text { comment }\end{array}$ \\
\hline & Medications history & Name of drug, drug dosage, additional comment \\
\hline
\end{tabular}


Table 6 (continued)

\begin{tabular}{|c|c|c|}
\hline Main class & Sub class & Data element \\
\hline \multirow[t]{2}{*}{ Previous history of COVID-19 } & History of COVID-19 & $\begin{array}{l}\text { Had a previous history of COVID-19, illness onset date, } \\
\text { disease severity status (mild, moderate and severe), } \\
\text { additional comment }\end{array}$ \\
\hline & History of COVID-19 vaccination & $\begin{array}{l}\text { History of COVID-19 vaccination, number of vaccine doses } \\
\text { received, date of administration }\end{array}$ \\
\hline
\end{tabular}

was exposed to infection, the exposure data was used in the coronavirus family data set. For instance, COVID-19 forms and dataset [37], British government MDS form for MERS disease [42], and MDS for SARS [35].

Another main issue with COVID-19 is the new variants of the virus. One of the principal concerns about the coronavirus variants is whether the mutations could affect treatment and prevention or not [43]. The importance of recording COVID-19 variants led to consider a subclass for infection with mutated strains of COVID-19 in the fifth phase of the study.

The third top group of MDS was dedicated to medical history and physical examination data. It included 22 subclasses for recording signs and symptoms of COVID19 at the time of admission, as well as documenting the patient's underlying medical conditions. From the beginning of the COVID-19 outbreak, much attention was paid to identifying the signs and symptoms of the disease and distinguishing it from other infectious diseases. Moreover, since the early studies in China showed that underlying medical conditions impact on COVID-19 outcome [44], in all forms, MDS or dataset, and health information systems related to COVID-19, the data elements of underlying medical conditions were considered. Furthermore, the information needs assessment phase indicated that most titles of COVID-19 research proposals submitted to AJUMS focused on the effect of underlying medical conditions on the outcome of COVID-19. In addition, most of the data elements in the two national COVID-19 recording and reporting systems of the Iranian Ministry of Health (Management of Communicative Disease Prevention and Control and MCMC system) are dedicated to recording the sign and symptoms and underlying diseases. Therefore, in the MDS of the COVID-19 registry system, a classified approach was used to define the symptoms and underlying diseases to record them more accurately.

The fourth top group of MDS was related to clinical diagnostic test findings. The purpose of the three main classes in this group was to record abnormal medical imaging, laboratory, and cardiology diagnostic tests in patients with COVID-19, especially those hospitalized. One of the most important of the data was medical imaging data. The findings of CT scan and chest $x$-ray play an essential role in the diagnosis, the clinical course of the disease, and the choice of treatment for patients with COVID-19 [45-47].

The importance of imaging data has encouraged the Iranian Ministry of Health, in collaboration with the Iranian Society of Radiology to propose a standard form for reporting medical imaging data in patients with COVID19 [48]. In the same manner, the Radiological Society of North America (RSNA) also has provided a standard classification for reporting CT scan findings on COVID19 [49]. The study indicated that laboratory diagnostic data and cardiology diagnostic tests were other essential data that medical specialists emphasized on registering them. The reason for this attention may be the importance of the data elements in the treatment of inpatients with COVID-19 [50-54].

Disease progress and outcome of treatment data were the next top group of MDS. The data shows a period of the disease and the outcome of care. If the data combine with other data such as age, sex, underlying medical conditions and comorbidity, and clinical diagnostic test findings, they can facilitate many statistical analysis and artificial intelligence data modeling that can be applied in reliable prediction about the outcome of the disease based on extracting hidden relationships among the clinical and non-clinical data [55-57].

Therefore, 52 data elements were considered to record clinical course (such as hospitalization), disease complications, treatment measures, and disease outcome. The disease complications and outcomes were considered essential data in other forms, MDSs, and data sets related to COVID-19. For example, Shanbehzadeh and KazemiArpanahi, in their study entitled "Development of minimal basic data set to report COVID-19", proposed two subclasses for data elements of disease complications and outcomes [13].

Another questionable issue related to the COVID-19 is the effectiveness of various medications on the treatment outcome. Although the forms and databases for recording and reporting COVID-19 do not usually mention the medications used to treat the patient, we have considered 
Table 7 Clinical diagnostic test findings data about a probable or confirmed case of COVID-19

\begin{tabular}{|c|c|c|}
\hline Main class & Sub class & Data element \\
\hline \multirow[t]{4}{*}{ Medical imaging } & Chest x-raytifindings & $\begin{array}{l}\text { Date, normal, ground-glass opacity (GGO), nodular opacities, linear opacities, nodu- } \\
\text { lar and linear opacities, cavitation, pneumothorax, pleural effusion, adenopathy, } \\
\text { atelectasis, patchy, cardiomegaly, consolidation, other(s), please specify }\end{array}$ \\
\hline & \multirow[t]{3}{*}{ CT scantffindings } & $\begin{array}{l}\text { Date, normal, ground-glass opacityit(GGO), tree in bud: (branching nodular and } \\
\text { linear opacities), crazy-paving, cavitation, pneumothorax, pneumothorax, pleural } \\
\text { effusion, adenopathy, atelectasis, patchy, consolidation, cardiomegaly }\end{array}$ \\
\hline & & $\begin{array}{l}\text { Pulmonary involvement detail: } \\
\text { Right lung only,illeft lung only, iboth lung, lupper zone, middle zone, lower zone }\end{array}$ \\
\hline & & Diagnosis, additional comment \\
\hline \multirow[t]{2}{*}{$\begin{array}{l}\text { Cardiology diagnostic } \\
\text { tests and procedures }\end{array}$} & Electrocardiogram (ECG or EKG) findings & $\begin{array}{l}\text { Date, normal, sinus bradycardia, sinus tachycardia, arrhythmias, long QT, other(s), } \\
\text { please specify }\end{array}$ \\
\hline & Echocardiography findings & $\begin{array}{l}\text { Date, normal, congestive heart failure (CHF), coronary artery disease (CAD), elevated } \\
\text { pulmonary pressure (PAP), mitral regurgitation [34], pulmonary regurgitation (PR), } \\
\text { tricuspid regurgitation (TR), other(s), please specify }\end{array}$ \\
\hline \multirow[t]{5}{*}{ Clinical laboratory tests } & Hematology test findings & $\begin{array}{l}\text { Date, hematocrit (HCT), hemoglobin ( } \mathrm{Hgb}, \mathrm{Hb}) \text {, mean corpuscular volume (MCV), } \\
\text { mean corpuscular hemoglobin concentration (MCHC), red cell distribution width } \\
(\mathrm{RDW}) \\
\text { White blood cell (WBC) count, lymphocytes, neutrophils, eosinophils, monocytes, } \\
\text { basophils }\end{array}$ \\
\hline & Biochemistry tests findings & $\begin{array}{l}\text { Date, creatine, serum glutamic oxaloacetic transaminase (SGOT/AST), serum } \\
\text { glutamic pyruvic transaminase (SGPT/ALT), alkaline phosphatase, bilirubin, blood } \\
\text { urea nitrogen (BUN), N-terminal pro brain natriuretic peptide (NT-proBNP), proc- } \\
\text { alcitonin (PCT), high-density lipoprotein cholesterol (HDL-C), troponin, albumin, } \\
\text { lactate }\end{array}$ \\
\hline & Arterial blood gas test findings & Date, $\mathrm{PaO}_{2}, \mathrm{PaCO}_{2}, \mathrm{pH}, \mathrm{HCO}_{3}, \mathrm{O}_{2} \mathrm{CT}, \mathrm{O}_{2}$ Sat, saturation \\
\hline & Hemostasis test & $\begin{array}{l}\text { Date, prothrombin time (PT), partial thromboplastin time (PTT), mean platelet } \\
\text { volume (MPV), D-dimer, International normalized ratio (INR) }\end{array}$ \\
\hline & Other diagnostic test & $\begin{array}{l}\text { Date, C-reactive protein (quantitative), interleukin } 6 \text { (IL-6), other(s) diagnostic test, } \\
\text { please specify }\end{array}$ \\
\hline
\end{tabular}

Table 8 Disease progress and outcome of treatment data in a probable or confirmed case of COVID-19

\begin{tabular}{|c|c|c|}
\hline Main class & Sub class & Data element \\
\hline \multirow[t]{3}{*}{ Admission to hospital } & Hospitalization & $\begin{array}{l}\text { Need for hospitalization, first date of admission to hospital, discharge date, discharge } \\
\text { status, hospital name, hospital type, hospital ID/code }\end{array}$ \\
\hline & Care in an intensive care unit & Receive care in an intensive care unit, Length of stay (LOS) in ICU \\
\hline & Receive ventilation and intubation & $\begin{array}{l}\text { Receive mechanical ventilation, the number of ventilator days, need to intubation, the } \\
\text { number of intubation days }\end{array}$ \\
\hline \multirow[t]{2}{*}{ OVID-19 Medications } & The main medications prescribed & $\begin{array}{l}\text { Date, chloroquine phosphate, hydroxychloroquine, kaletra (lopinavir/ritonavir), ribavirin, } \\
\text { remdesivir, avipiravir, oseltamivir (tamiflu), Atazanavir/ritonavir, plasma transfusion, } \\
\text { other(s), please specify, additional comment }\end{array}$ \\
\hline & The auxiliary medications prescribed & $\begin{array}{l}\text { Date, naproxen, azithromycin, IVIG, sofosbuvir/daclatasvir (Sovodak), other(s), please } \\
\text { specify, additional comment }\end{array}$ \\
\hline \multirow[t]{7}{*}{$\begin{array}{l}\text { Disease complica- } \\
\text { tions and outcome }\end{array}$} & Systemic complications & $\begin{array}{l}\text { Sepsis/septic shock, multisystem inflammatory syndrome in children (MIS-C), multiorgan } \\
\text { failure, cytokine release syndrome, acute kidney injury (AKI), acute liver injury, hepatitis }\end{array}$ \\
\hline & Respiratory complications & Pneumonia, 'acute respiratory distress syndrome (ARDS), respiratory failure \\
\hline & Cardiovascular complications & $\begin{array}{l}\text { Myocardial infarction, heart failure, arrhythmias, acute coronary syndrome, endothelialitis, } \\
\text { vasculitis, viral myocarditis, other cardiovascular complications }\end{array}$ \\
\hline & Hematologic complications & $\begin{array}{l}\text { Disseminated intravascular coagulation (DIC), thrombocytopenia, leukocytosis, leukocy- } \\
\text { topenia, pulmonary embolism (PE), deep vein thrombosis (DVT) }\end{array}$ \\
\hline & Neurologic complications & $\begin{array}{l}\text { Cerebrovascular accident (CVA), meningitis, encephalopathy, other neurologic complica- } \\
\text { tions }\end{array}$ \\
\hline & Other complications & Date, the name of complications, additional comment \\
\hline & Outcome & Recovered/healthy, death, not recovered, other(s), please specify \\
\hline
\end{tabular}


Table 9 Medical diagnosis and cause of death data in a probable or confirmed case of COVID-19

\begin{tabular}{lll}
\hline Main class & Sub class & Data element \\
\hline Medical diagnosis & $\begin{array}{l}\text { Primary diagnosis/impression } \\
\text { final diagnosis }\end{array}$ & $\begin{array}{l}\text { Date, Primary diagnosis ICD10 code } \\
\text { Principal diagnosis ICD10 code, secondary } \\
\text { diagnoses ICD10 code } \\
\text { Principal procedure code, other procedure code }\end{array}$ \\
$\begin{array}{ll}\text { Medical procedure } \\
\text { Cause of death }\end{array}$ & Medical procedure & Medical diagnosis, ICD10 code \\
& Direct cause of death & Medical diagnosis, ICD10 code \\
& Intermediate causes of death & Medical diagnosis, ICD10 code \\
\hline
\end{tabular}

Table 10 Follow-up data in a probable or confirmed case of COVID-19

\begin{tabular}{llc}
\hline Main class & Sub class & Data element \\
\hline $\begin{array}{l}\text { Patient's follow-up } \\
\text { Patient status until } 2 \text { weeks after dis- } \\
\text { charge/quarantine }\end{array}$ & $\begin{array}{c}\text { Quarantine location (home, recovery camp and others) } \\
\text { Patient status in the 1st week (isolation/quarantine according to the standards for COVID- } \\
19 \text { patients, quarantine without safety protocols, return to work, exacerbation of the } \\
\text { disease, unspecified) } \\
\text { Patient status in the } 2 \text { nd week (isolation/quarantine according to the standards for COVID- } \\
19 \text { patients, quarantine without safety protocols, return to work, exacerbation of the } \\
\text { disease, unspecified) }\end{array}$ \\
$\begin{array}{c}\text { Symptoms of the disease after discharge } \\
\text { Dry cough, shortness of breath, constant pain or pressure in chest, tiredness, loss of } \\
\text { smell or taste, loss of appetite, other(s), please specify, date of the last symptom } \\
\text { Date of contact, delivery mode, responsive person (if the respondent is not patient } \\
\text { himself/herself), reporting person }\end{array}$
\end{tabular}

Table 11 COVID-19 vaccinationtidata

\begin{tabular}{|c|c|c|}
\hline Main class & Sub class & Data element \\
\hline \multirow[t]{2}{*}{ COVID-19 vaccinationtidata } & COVID-19 Vaccine Administration data & $\begin{array}{l}\text { COVID-19 vaccine (Oxford-AstraZeneca, Sputnik V, } \\
\text { Sinopharm, etc.), date the first dose adminis- } \\
\text { tration, date the second dose administration, } \\
\text { places to provide the COVID-19 vaccine (health } \\
\text { center ID, name, address) }\end{array}$ \\
\hline & Vaccine side effect & $\begin{array}{l}\text { Date, pain at the injection site, tiredness, head- } \\
\text { ache, muscle or joint pain, chills, fever, fatigue, } \\
\text { nausea and vomiting, diarrhea, swollen lymph } \\
\text { nodes, severe allergic reaction (difficulty breath- } \\
\text { ing, dizziness, swelling of the face and throat, } \\
\text {...), thrombosis, thrombocytopenia, other(s), } \\
\text { please specify }\end{array}$ \\
\hline
\end{tabular}

a separate class for medications because the topic is important for medical research.

The data elements related to medications may help to identify the effects of different medications in the treatment of COVID-19.

The top group for medical diagnosis and cause of death data was considered to record the relationship between primary and final diagnosis and the cause of death in patients with COVID-19.

The group included diagnostic (based on WHO's ICD10 classification system), causes of death, and medical procedures codes (based on ICD9CM Volume 3).
Clinical coding of medical records can help to manage statistical data about diseases and causes of death at the national or international levels [58]. Therefore, that data could facilitate retrieving information about patients with COVID-19 in the future. Most studies conducted to design MDS of diseases have suggested using diagnostic data elements [16, 27, 29].

Coinciding with the COVID-19 Pandemic, the WHO proposed new ICD codes for the disease to help classify and report it. WHO also published a guideline for recording and coding the causes of death due to COVID19 [59]. In addition to WHO efforts, some countries have 
established a process to record COVID-19 coding data. For example, in the Irish COVID-19 data set, "diagnosis concepts" is considered for recording diagnostic data [60]. Also, in the United States, several guidelines were published by the CDC, AHIMA, and AMA regarding the recording and coding of diagnoses and medical procedures for COVID-19 [13, 61, 62]. As the same manner, Iran's Ministry of Health has already issued three guidelines for coding COVID-19 [48].

The top group was follow-up data. In the group, data related to patient monitoring up to 2 weeks after discharge from the hospital or quarantine at home was recorded.

The patient follow-up is important for two reasons: firstly, to ensure that the signs and symptoms of the disease improve, and secondly, to track people who are in close contact with the patient. Therefore, the patient follow-up is essential protocols in controlling COVID-19 especially for a patient who is in quarantine at home.

Another fundamental way to effectively control the disease is vaccination. COVID-19 vaccination started in March 2021 in Ahvaz. Therefore, at the beginning of vaccination, we considered a top group of MDS to record its data. Recording vaccination information is valuable in several ways. Firstly, the data can be used to evaluate the effectiveness of different vaccines. Secondly, they help to evaluate the vaccination effectiveness on disease control. Finally, the data can aid in assessing the side effects of vaccines.

\section{Conclusion}

The MDS designed in the present study has tried as much as possible to cover the essential data for the COVID-19 registry system. Using a comprehensive MDS and a systematic approach to data collection of COVID-19 can provide valuable information for health policymakers, researchers, and clinical specialists.

Given the importance of having accurate, complete, and up-to-date information on COVID-19 disease control, it strongly recommends that different countries should design a comprehensive national MDS for COVID-19. The methodology used in this study can also help other developing countries that do not have a comprehensive infrastructure for disease recording and reporting systems to implement similar disease registry systems.

\section{Limitation of study}

At the beginning of the project, there were few related studies to our topic. Also, due to the difficulty in longterm follow-up of patients, data elements have not been considered for long-term COVID-19 complications.

\section{Further study}

We recommend that future studies can focus on the effectiveness of the COVID-19 registry system in data quality. Also, we strongly recommend that an international MDS be designed for the long-term complications of COVID-19.

\begin{abstract}
Abbreviations
AHIMA: American Health Information Management Association; AJUMS: Ahvaz Jundishapur University of Medical Sciences; AKI: Acute kidney injury; AMA: American Medical Association; ARDS: Acute respiratory distress syndrome; BMI: Body mass index; BUN: Blood urea nitrogen; CAD: Coronary artery disease; CDC: Center for Disease Control; CHF: Congestive heart failure; CKD: Chronic kidney disease; COPD: Chronic obstructive pulmonary disease; CRP: C-reactive protein; CVA: Cerebra vascular accident; DIC: Disseminated intravascular coagulation; GCS: Glasgow coma scale/score; Hb: Hemoglobin; HCT: Hematocrit; HIS: Hospital information system; ICTV: International Committee on Taxonomy of Viruses; ILD: Interstitial lung disease; INR: International normalized ratio; LDH: Lactic acid dehydrogenase; LOS: Length of stay; MCHC: Mean corpuscular hemoglobin concentration; MCMC: Medical Care Monitoring Center System; MCV: Mean corpuscular volume; MDS: Minimum data set; MS: Multiple sclerosis; NT-proBNP: N-terminal pro brain natriuretic peptide; PCT: Procalcitonin; PR: Pulmonary regurgitation; PT: Prothrombin time; PTT: Partial thromboplastin time; RAD: Rapid Application Development; RDW: Red cell distribution width; TR: Tricuspid regurgitation; WBC: White blood cell; WHO: World Health Organization.
\end{abstract}

\section{Acknowledgements}

Authors are express gratitude and appreciation for cooperating of Dr. Ali Mohammad Hadianfard for editing the manuscript.

\section{Authors' contributions}

JZ: Study conception and design, drafting the manuscript. MB, MK: consult scientific. MHS, HR: data collection. MD: data analysis. FY: study conception. MC: supervised the research, study conception, critical revision. All authors read and approved the manuscript.

\section{Funding}

Deputy of Research in Ahvaz Jundishapur University of Medical Sciences has found this project for implementation during pandemic disease of COVID-19 in the world. But this fund is no effect on the design of the study and collection, analysis, and interpretation of data and in writing the manuscript.

\section{Availability of data and materials}

The datasets used during the current study are available from the first author on reasonable request.

\section{Declarations}

Ethics approval and consent to participate

Ethical issues such as plagiarism, data fabrication, data falsification, conflict of interest, misconduct, double publication and/or submission, redundancy, etc. have been completely observed by the authors. Ethics committee of Ahvaz Jondishapur University of Medical Sciences, Ahvaz, Iran approved the study with Ethical approval code: IR.AJUMS.REC.1399.061. Written informed consent was obtained from all participants in this study.

Consent for publication

Not applicable.

\section{Competing interests}

The authors state that there is no competing of interest in this article.

\section{Author details}

${ }^{1}$ Department of Health Information Technology, School of Allied Medical Sciences, Ahvaz Jundishapur University of Medical Sciences, Ahvaz, Iran. 
${ }^{2}$ Department of Physiology, School of Medicine, Physiology Research Center, Ahvaz Jundishapur University of Medical Sciences, Ahvaz, Iran. ${ }^{3}$ Nutrition and Metabolic Diseases Research Center, Ahvaz Jundishapur University of Medical Sciences, Ahvaz, Iran. ${ }^{4}$ Air Pollution and Respiratory Diseases Research Center, Ahvaz Jundishapur University of Medical Sciences, Ahvaz, Iran. ${ }^{5}$ Department of Biostatistics and Epidemiology, Social Determinants of Health Research Center, Ahvaz Jundishapur University of Medical Sciences, Ahvaz, Iran. ${ }^{6}$ Infectious and Tropical Diseases Research Center, Health Research Institute, Ahvaz Jundishapur University of Medical Sciences, Ahvaz, Iran. ${ }^{7}$ Department of Infectious Diseases, School of Medicine, Razi Hospital, Ahvaz Jundishapur University of Medical Sciences, Ahvaz, Iran. ${ }^{8}$ Social Determinant of Health Research Center, Department of Public Health, School of Health, Ahvaz Jundishapur University of Medical Sciences, Ahvaz, Iran.

Received: 6 August 2020 Accepted: 30 July 2021 Published online: 09 August 2021

\section{References}

1. WHO Coronavirus (COVID-19) dashboard. https://covid19.who.int/.

2. Zarei J, Dastoorpoor M, Jamshidnezhad A, Cheraghi M, Sheikhtaheri A. Regional COVID-19 registry in Khuzestan, Iran: a study protocol and lessons learned from a pilot implementation. Inform Med Unlocked. 2021;23:100520.

3. Alaran AJ, Adebisi YA, Badmos A, Khalid-Salako F, llesanmi EB, Olaoye DQ, Bamisaiye A, Lucero-Prisno DE III. Uneven power dynamics must be levelled in COVID-19 vaccines access and distribution. Public Health Pract. 2021;2:100096

4. Shrestha GS, Lamsal R. Rational use of oxygen in COVID-19 pandemic-are we doing enough? J Nepal Med Assoc. 2021;59(236):429-31.

5. Acharya KP, Ghimire TR, Subramanya SH. Access to and equitable distribution of COVID-19 vaccine in low-income countries. npj Vaccines. 2021;6(1):1-3

6. Zhao S, Lou J, Chong MK, Cao L, Zheng H, Chen Z, Chan RW, Zee BC, Chan PK, Wang MH. Inferring the association between the risk of COVID-19 case fatality and N501Y substitution in SARS-CoV-2. Viruses. 2021;13(4):638

7. Forni G, Mantovani A. COVID-19 vaccines: where we stand and challenges ahead. Cell Death Differ. 2021;28:626-39.

8. Ahmed K, Bukhari MA, Mlanda T, Kimenyi JP, Wallace P, Lukoya CO, Hamblion EL, Impouma B. Novel approach to support rapid data collection, management, and visualization during the COVID-19 outbreak response in the world health organization African region: development of a data summarization and visualization tool. JMIR Public Health Surveill. 2020;6(4):e20355

9. Kodra Y, Weinbach J, Posada-de-la-Paz M, Coi A, Lemonnier SL, van Enckevort D, Roos M, Jacobsen A, Cornet R, Ahmed SF. Recommendations for improving the quality of rare disease registries. Int J Environ Res Public Health. 2018;15(8):1644

10. Nouhjah S, Shahbazian H, Zarei J, Sharifi M. Designing a data set for postpartum recall registry of women with gestational diabetes in recent pregnancy and its implementation in Iranian urban health centers. Diabetes Metab Syndr. 2021;15(1):1-6.

11. Domensino A-F, Winkens I, van Haastregt JC, van Bennekom CA, van Heugten CM. Defining the content of a minimal dataset for acquired brain injury using a Delphi procedure. Health Qual Life Outcomes. 2020;18(1):1-10.

12. Abbasi R, Khajouei R, Mirzaee M. Evaluating the demographic and clinical minimum data sets of Iranian National Electronic Health Record. BMC Health Serv Res. 2019;19(1):1-10.

13. Shanbehzadeh M, Kazemi-Arpanahi H. Development of minimal basic data set to report COVID-19. Med J Islam Repub Iran. 2020;34:111.

14. Shanbehzadeh M, Ahmadi M. Identification of the necessary data elements to report AIDS: a systematic review. Electron Physician. 2017;9(12):5920.

15. Ahmadi M, Madani T, Alipour J. Development a national minimum data set (MDS) of the information management system for disability in Iran. Disabil Health J. 2019;12(4):641-8.
16. Ahmadi M, Mohammadi A, Chraghbaigi R, Fathi T, Baghini MS. Developing a minimum data set of the information management system for orthopedic injuries in iran. Iran Red Crescent Med J. 2014;16(7):e17020.

17. Shanbehzadeh M, Kazemi-Arpanahi H, Mazhab-Jafari K, Haghiri H. Coronavirus disease 2019 (COVID-19) surveillance system: development of COVID-19 minimum data set and interoperable reporting framework. J Educ Health Promot. 2020;9:203.

18. Bitarafan B, Jahanshahi A, Shahbazian H, Nooshabadi Z. Designing a minimum data set for thyroid cancer in Iran. Int J Cancer Manage. 2020 https://doi.org/10.5812/ijcm.96997.

19. Rampisheh Z, Kameli ME, Zarei J, Barzaki AV, Meraji M, Mohammadi A. Developing a national minimum data set for hospital information systems in the Islamic Republic of Iran. East Mediterr Health J. 2020;26(4):400-9.

20. COVID-19 REGISTRATION FORM. https://sa1s3.patientpop.com/assets/ docs/247043.pdf

21. Weingart SN, lezzoni LI, Davis RB, Palmer RH, Cahalane M, Hamel MB, Mukamal K, Phillips RS, Davies DT Jr, Banks NJ. Use of administrative data to find substandard care: validation of the complications screening program. Med Care. 2000;38:796-806.

22. Javanmard SH, Nasirian M, Ataei B, Vaseghi G, Vaezi A, Changiz T. Isfahan COvid-19 REgistry (I-CORE): design and methodology. J Res Med Sci. 2020;25:32

23. Talebpour M, Hadadi A, Oraii A, Ashraf H. Rationale and design of a registry in a referral and educational medical center in Tehran, Iran: Sina Hospital Covid-19 Registry (SHCo-19R). Front Emerg Med. 2020;4(2s):e53-e53.

24. Khorrami F, Shahi M, DavariDolatabadi N, Karami NA, HasaniAzad M, Jafariyan F, Sheikhtaheri A. Implementation of regional COVID-19 registry in Hormozgan (RCovidRH), Iran: rationale and study protocol. Med J Islam Repub Iran. 2020;34:96.

25. Emami A, Akbari A, Javanmardi F, Lotfi M, Moghadami M, Sharifi M, Bakhtiari $\mathrm{H}$, Falahati F. Designing a multicenter registry of COVID-19 and other respiratory infections in Fars, Iran. Disaster Med Public Health Prep. 2021. https://doi.org/10.1017/dmp.2021.100.

26. Kazemi-Arpanahi H, Moulaei K, Shanbehzadeh M. Design and development of a web-based registry for Coronavirus (COVID-19) disease. Med J Islam Repub Iran. 2020;34:68.

27. Rampisheh Z, Kameli M, Zarei J, Vahedi Barzaki A, Meraji M, Mohammadi A. Developing a national minimum data set for hospital information systems in the Islamic Republic of Iran. East Mediterr Health J. 2019;25:400-9.

28. Abbasi M, Ahmadian L, Amirian M, Tabesh H, Eslami S. The development of a minimum data set for an infertility registry. Perspect Health Inf Manage. 2018;15(Winter):1b.

29. Ahmadi M, Alipour J, Mohammadi A, Khorami F. Development a minimum data set of the information management system for burns. Burns. 2015:41(5):1092-9.

30. Hayrinen K, Saranto K. The core data elements of electronic health record in Finland. Stud Health Technol Inform. 2005;116:131-6.

31. Nsw Health Client Data Stream Data Dictionary. https://www.health.govt. nz/system/files/documents/publications/nmds_data_dictionary_v7.8. pdf.

32. COVID-19 Dataset Specification. Ver 06. Irish National Release Centre (NRC); 2020.

33. National Health Board. National Minimum Dataset (Hospital Events) DATA DICTIONARY, vol. 7.9.1. Wellington: Ministry of Health; 2014

34. Zhan C, Miller M. Administrative data based patient safety research: a critical review. Qual Saf Health Care. 2003;12(suppl 2):ii58-63.

35. Scott RD 2nd, Gregg E, Meltzer MI. Collecting data to assess SARS interventions. Emerg Infect Dis. 2004;10(7):1290-2.

36. Sane J, Edelstein M. Overcoming barriers to data sharing in public health. A global perspective. London: Chatham House; 2015.

37. World Health Organization. Revised case report form for confirmed novel Coronavirus COVID-19 (report to WHO within 48 hours of case identification). Geneva: WHO; 2020.

38. Stanfill M, Giannangelo K, Fenton S. Health information management best practices for quality health data during the COVID-19 global pandemic. In: Perspectives in health information management, vol. Winter 2020; 2020.

39. De Coster C, Quan H, Finlayson A, Gao M, Halfon P, Humphries $\mathrm{KH}$, Johansen $\mathrm{H}$, Lix LM, Luthi J-C, Ma J. Identifying priorities in 
methodological research using ICD-9-CM and ICD-10 administrative data: report from an international consortium. BMC Health Serv Res. 2006;6(1):77.

40. Wager KA, Lee FW, Glaser JP. Managing health care information systems: a practical approach for health care executives. Hoboken: Wiley; 2005.

41. Zhan C, Miller M. Administrative data based patient safety research: a critical review. BMJ Qual Saf. 2003:12(suppl 2):ii58-63.

42. MERS-CoV: minimum data set form for possible cases. https://www.gov uk/government/publications/mers-cov-minimum-data-set-form-forpossible-cases.

43. Le Page M. Threats from new variants. Amsterdam: Elsevier; 2021.

44. Yang $C$, Jin Z. An acute respiratory infection runs into the most common noncommunicable epidemic-COVID-19 and cardiovascular diseases. JAMA Cardiol. 2020;5(7):743-4. https://doi.org/10.1001/jamacardio.2020. 0934

45. Bernheim A, Mei X, Huang M, Yang Y, Fayad ZA, Zhang N, Diao K, Lin B, Zhu X, Li K. Chest CT findings in coronavirus disease-19 (COVID-19): relationship to duration of infection. Radiology. 2020;295:200463.

46. LiY, Xia L. Coronavirus disease 219 (COVID-19): role of chest CT in diagnosis and management. Am J Roentgenol. 2020:214:1280-6.

47. Tenda ED, Yulianti M, Asaf MM, Yunus RE, Septiyanti W, Wulani V, Pitoyo CW, Rumende CM, Setiati S. The importance of chest CT scan in COVID19. Acta Med Indones. 2020;52(1):68-73.

48. The Ministry of Health and Medical Education. Diagnosis recording and coding instructions of COVID-19, based on the 10th revision of the International Statistical Classification of Diseases and Related Health Problems (ICD 10), Version2. Tehran: The Ministry of Health and Medical Education; 2020

49. Reporting of COVID-19 chest CT findings. https://radiopaedia.org/cours es/reporting-of-covid-19-ct-chest-findings.

50. Fan BE, Chong VCL, Chan SSW, Lim GH, Lim KGE, Tan GB, Mucheli SS, Kuperan P, Ong KH. Hematologic parameters in patients with COVID-19 infection. Am J Hematol. 2020;95:E215.

51. Tian S, Liu H, Liao M, Wu Y, Yang C, Cai Y, Peng Z, Xiao S-Y. Analysis of mortality in patients of COVID-19: clinical and laboratory parameters. In: Open forum infectious diseases. Oxford: Oxford University Press.

52. Inciardi RM, Lupi L, Zaccone G, Italia L, Raffo M, Tomasoni D, Cani DS, Cerini M, Farina D, Gavazzi E. Cardiac involvement in a patient with coronavirus disease 2019 (COVID-19). JAMA Cardiol. 2020:5(7):81924. https://doi.org/10.1001/jamacardio.2020.1096.

53. Skulstad H, Cosyns B, Popescu BA, Galderisi M, Salvo GD, Donal E, Petersen S, Gimelli A, Haugaa KH, Muraru D. COVID-19 pandemic and cardiac imaging: EACVI recommendations on precautions, indications, prioritization, and protection for patients and healthcare personnel. Eur Heart J-Cardiovasc Imaging. 2020;21(6):592-8.

54. Liu Y, Du X, Chen J, Jin Y, Peng L, Wang HH, Luo M, Chen L, Zhao Y. Neutrophil-to-lymphocyte ratio as an independent risk factor for mortality in hospitalized patients with COVID-19. J Infect. 2020;81:e6-12.

55. Zhou F, Yu T, Du R, Fan G, Liu Y, Liu Z, Xiang J, Wang Y, Song B, Gu X. Clinical course and risk factors for mortality of adult inpatients with COVID-19 in Wuhan, China: a retrospective cohort study. Lancet. 2020;395:1054-62.

56. Petrilli CM, Jones SA, Yang J, Rajagopalan H, O'Donnell LF, Chernyak Y, Tobin K, Cerfolio RJ, Francois F, Horwitz LI. Factors associated with hospitalization and critical illness among 4,103 patients with COVID-19 disease in New York City. MedRxiv. 2020

57. Guo T, Fan Y, Chen M, Wu X, Zhang L, He T, Wang H, Wan J, Wang X, Lu Z. Cardiovascular implications of fatal outcomes of patients with coronavirus disease 2019 (COVID-19). JAMA Cardiol. 2020:5:811.

58. Organization WH. ICD-10: international statistical classification of diseases and related health problems: tenth revision. Geneva: WHO; 2004

59. Emergency use ICD codes for COVID-19 disease outbreak. https://www. who.int/classifications/icd/covid19/en/.

60. Mounesan L, Eybpoosh S, Haghdoost A, Moradi G, Mostafavi E. Is reporting many cases of COVID-19 in Iran due to strength or weakness of Iran's health system? Iran J Microbiol. 2020;12(2):73-6.

61. International Classification of Diseases, tenth revision, clinical modification (ICD-10-CM). https://www.cdc.gov/nchs/icd/icd10cm.htm.

62. COVID-19 News \& Resources. https://www.ahima.org/topics/covid-19.

\section{Publisher's Note}

Springer Nature remains neutral with regard to jurisdictional claims in published maps and institutional affiliations.
Ready to submit your research? Choose BMC and benefit from:

- fast, convenient online submission

- thorough peer review by experienced researchers in your field

- rapid publication on acceptance

- support for research data, including large and complex data types

- gold Open Access which fosters wider collaboration and increased citations

- maximum visibility for your research: over $100 \mathrm{M}$ website views per year

At BMC, research is always in progress.

Learn more biomedcentral.com/submissions 